IP Periodica Polytechnica

Mechanical Engineering

57(1), pp. 35,40 2013

DOI: 10.3311/PPme.7015

Creative Commons Attribution (1)

RESEARCH ARTICLE

\section{Thermal FE analysis of a one side brake block test equipment (Part 2)}

\author{
Gábor Fekete, Károly Váradi
}

Received 2013-04-30

\begin{abstract}
The paper includes the second part of an investigation of the braking process of railway vehicles, dealing with the temperature distribution of a brake block in various load cases and the FE analysis of the phenomenon of thermal elastic deformation. Thermal expansion calculations pointed out to the fact that in case of the contact area, the radius of the operating surface of the brake block increases as a result of warming up. In the course of braking, the brake block of increased radius wears off to the size of the wheel, and after cooling down the radius of the operating surface will be smaller than the radius of the wheel, therefore at the next braking phase the two edges of the brake block will first contact with the wheel. The paper deals with the thermal expansion of a worn brake block as well to compare the $F E$ results with the measured worn data. It was found that the thermal expansion of the brake block is less significant than the effect of the wear on the deformation of the brake block profile.
\end{abstract}

\section{Keywords}

FEM $\cdot$ railway brake block $\cdot$ heat load $\cdot$ heat expansion $\cdot$ opening

\section{Acknowledgement}

The authors are grateful to Professor István Zobory for his valuable advices.This work is connected to the scientific program of the "Development of quality-oriented and harmonized $R+D+I$ strategy and functional model at BME" project. This project is supported by the New Hungary Development Plan (Project ID: TÁMOP-4.2.1/B-09/1/KMR-2010-0002).

\section{Gábor Fekete}

Department of Machine and Product Design, BME, H-1111 Múegyetem rkp. 3, Hungary

e-mail: fekete.gabor@gt3.bme.hu

\section{Károly Váradi}

Department of Machine and Product Design, BME, H-1111, Múegyetem rkp. 3, Hungary

e-mail: varadik@eik.bme.hu

\section{Introduction}

The first part of this paper expounded the thermal FE analysis of a brake block test equipment suitable for the simulation of railway brake blocks. In the course of examining the steady state of the entire model, the proportion of heat power transferred to the brake block was determined, representing the thermal load of the brake block. This is followed by thermo-mechanical calculations related to the thermal expansion of the small sample brake block. As the braking process progresses, heat generation increases at the edges of the block, coupled with wear processes to increase the contact area of the brake block and the wheel, starting from the edge of the block towards the inside area. Within the contact area, strength properties are decreased and thermal expansion occurs. As a consequence, the radius of curvature of the block increases, it will "open" and internal points will also get into contact in the course of braking, representing the joint effect of wear and thermal expansion [1]. Similar behaviour was obtained during other investigations [2] for the brake block opening process. In this literature the brake block was cooled down from $400^{\circ} \mathrm{C}$ to uniform temperature $\left(20^{\circ} \mathrm{C}\right)$ to represent an intensive braking process inversed. After cooling down (at uniform temperature) the radius of the brake block was about $120.5 \mathrm{~mm}$ and it was $121 \mathrm{~mm}$ at $400^{\circ} \mathrm{C}$, so the change of the radius was about $500 \mu \mathrm{m}$. Afterwards, heat generation starts in the internal parts as well, differences in the temperature of external and internal parts are reduced, therefore the radius of curvature will also decrease. A 3D model is required to be applied to model the phenomenon accurately in case of a brake block test equipment as well [3]. The CosmosWorks software was used for FE analyses. (The test equipment (see in Part 1) was investigated with a single side brake block configuration).

\section{The brake block and wheel thermal models with ref- erence points}

Fig. 1 presents the model of the brake block and the wheel. Points "B" and "C", are located in the middle of the upper edge of the brake block and in the centre of the contact area, respectively, indicating temperature control points in the simulations to be described later on. Point " $D$ " is located opposite to point 
"B" in a symmetrical position. The coordinate system of the brake block is also shown in Fig. 1 .
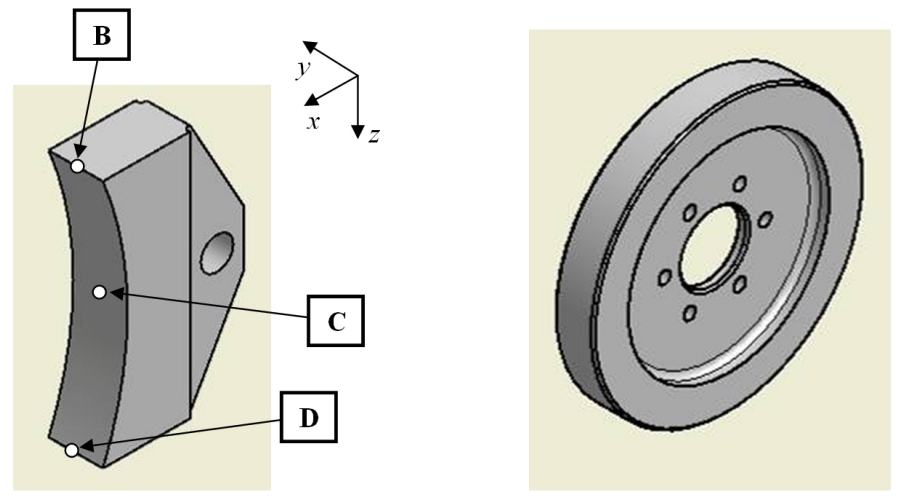

Fig. 1. Brake block with the reference points and wheel model

\section{Modelling of block "opening"}

In the course of sliding contact between the brake block and the wheel, the brake block deforms as a result of its elastic mechanical deformation due to the contact behaviour to a lesser extent, and its thermal expansion. During the simulation, structural and thermal analyses were performed, enabling tests of the mechanical deformation and thermal expansion of the block. The steps of this cyclical analysis are shown in a block diagram in Fig.2

The thermal load $\left(Q_{1}=Q_{2}=\ldots=Q_{i}\right)$ of the FE model was determined based on the operating conditions described in Part 1 of this paper. The thermal FE simulations in each cycle of the block opening process were performed as transient simulations where the time increment was $0.8 \mathrm{sec}$ and the time interval was $6.4 \mathrm{sec}$. Parameter $i$ shows the cycle number of the simulated braking process. The thermal loads were applied on the contact surfaces $\left(A_{i}\right)$ of the brake block resulted by the solution of a previous contact analysis in each $i$ cycle.

At the first step in the investigation of brake block opening, a contact calculation (Fig. 3) was performed using the starting geometry of the brake block, resulting the contact surface $A_{1}$. (The original radius of the contact surface of the brake block was set as $121 \mathrm{~mm}$, the radius of the wheel model was considered as 125 $\mathrm{mm}$ in order to model the edge contact with worn assumed brake block geometry. The significant difference between the radius of the connected parts is only for representing.) In the first step the temperature of the block corresponded to environment temperature, therefore no thermal expansion occurred.) In the next step, heat partition for the entire test equipment (49W) was defined for the surface $A_{1}$ (Fig. 5) of the model including mechanical deformation (during the solution of the contact problem) and thermal load. The temperature distribution produced in this step of the transient thermal calculation enabled the completion of another connected static structural calculation (contact and thermal expansion), providing the changed contact surface $A_{i}$ as an input parameter for the transient thermal problem defined in the next step.

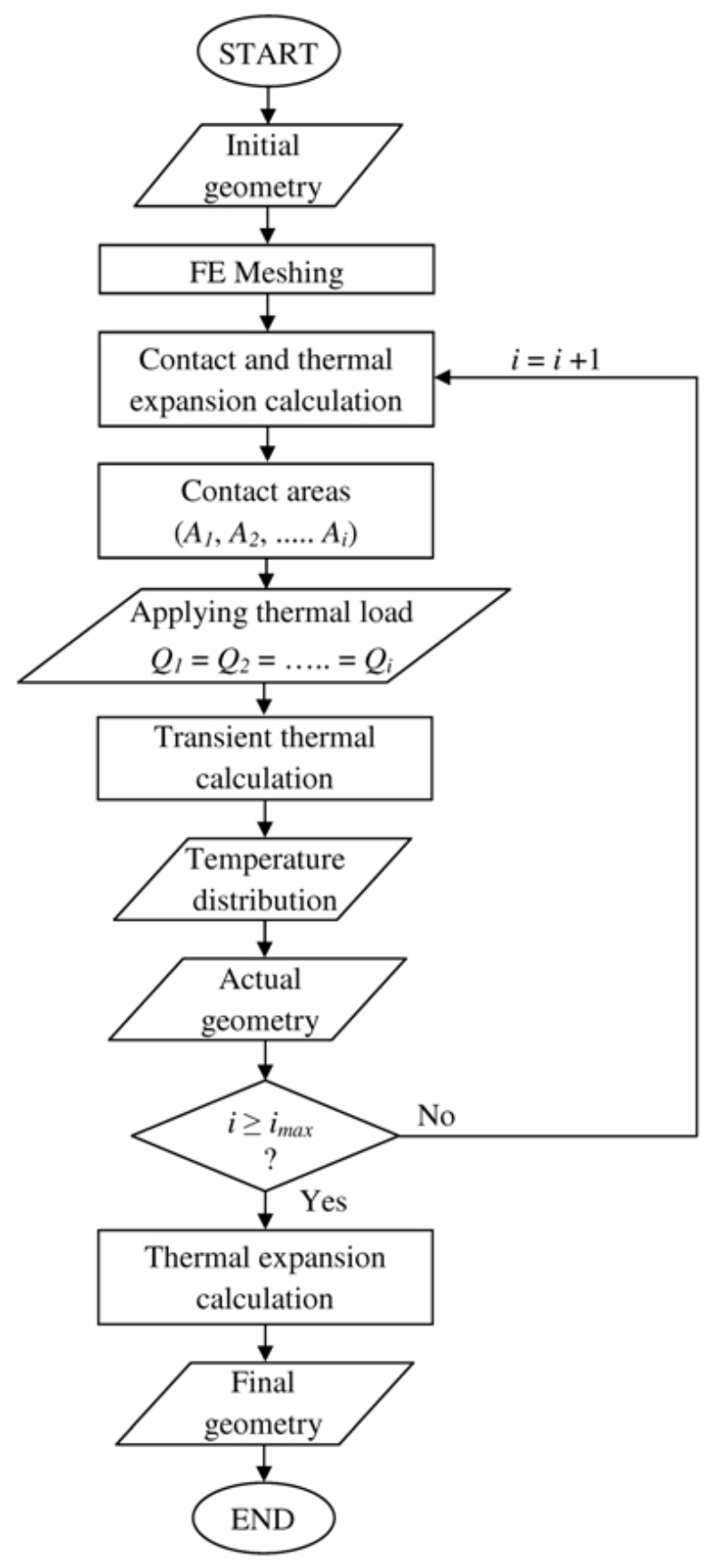

Fig. 2. Block diagram of brake block opening calculations

\section{The simplified FE model}

A simplified FE model was prepared to analyze the contact problem between the brake block and the wheel. The structural model is shown in Fig. 3 and contained two components: a segment of the railway wheel was fixed and the brake block was pressed against the surface of the wheel with a normal force $\left(F_{N}=100 \mathrm{~N}\right)$. The friction force on the surface was not considered, because symmetric contact regions were assumed. The FE mesh was made up of 10-node tetrahedron elements with an average element size of $3 \mathrm{~mm}$ ( $1 \mathrm{~mm}$ in the contact area). The convective heat transfer coefficient defined on the proper surfaces of the brake block was $18 \mathrm{~W} / \mathrm{m}^{2} \mathrm{~K}$. The rest of the material data is the same as in Part 1 . Thermal processes were not considered on the wheel, because of the heat partition approach on the brake block. 


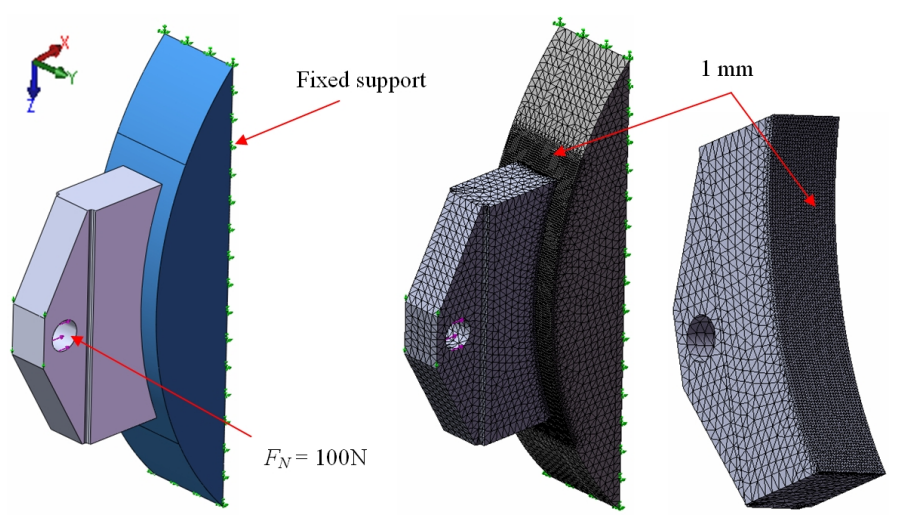

Fig. 3. Simplified FE model and FE mesh

Fig. 4 presents the contact areas during the simulation cycles. The contact areas were the same on the top and on the bottom side of the brake block.

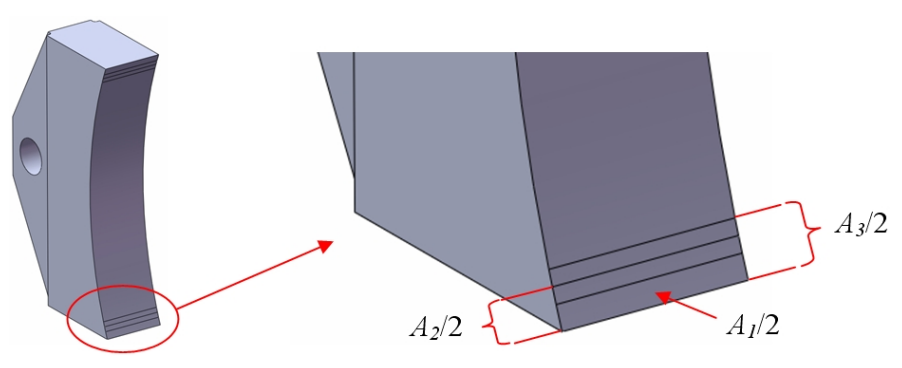

Fig. 4. Contact areas on the brake block friction surface

\section{Results}

Calculation experience showed that the contact area at the connection of brake block and wheel did not change after the 3rd cycle. This suggest that the phenomenon of wear is required to be taken into consideration in order to determine precisely the contact area produced in further steps of the contact problem analysis (see in section 5.2). As the thermal model is not suitable for this, the contact area produced in the 3rd cycle was applied in further cycles. Fig. 5illustrates the contact surfaces produced in the first three cycles, to which thermal load was applied.
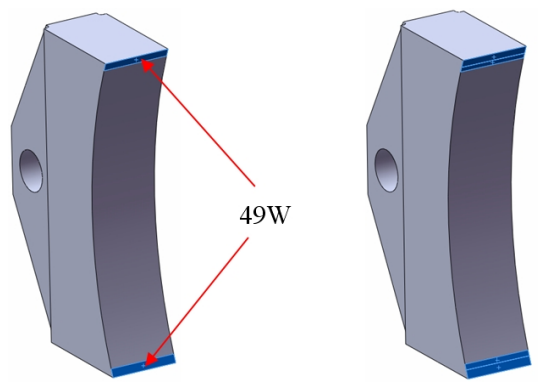

Fig. 5. Contact areas produced in the first 3 cycles

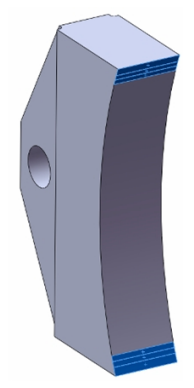

\subsection{Operating force $\mathrm{F}=100 \mathrm{~N}$ (opening process)}

Brake block temperatures were depicted at discrete time moments of subsequent cycles (Fig. 6).
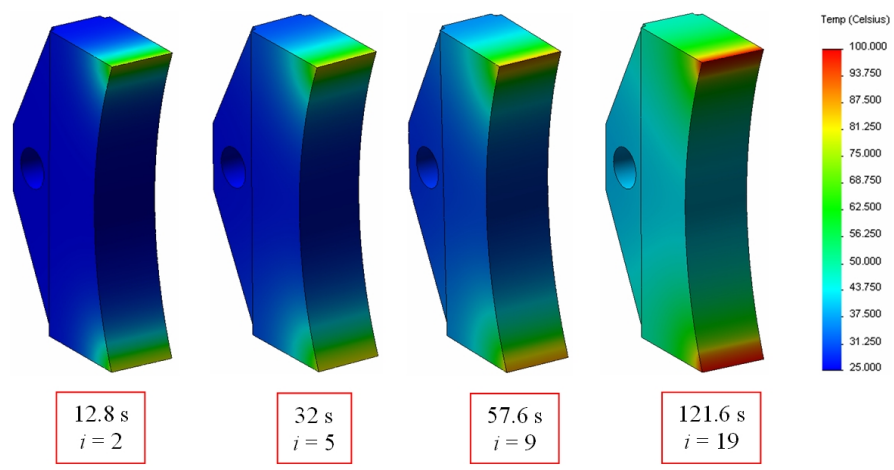

Fig. 6. Brake block temperature distribution at discrete time moments

Fig. 7 shows the changes of temperature values in time at points "B" and "C" of a brake block (Fig. 1) heated at the corners. Based on Fig. 7 it can be estimated that heat-up is much more intensive at point " $\mathrm{B}$ " of the model loaded at the edges than in point " $\mathrm{C}$ " in the centre. The maximum difference is about $50^{\circ} \mathrm{C}$ between the two points.

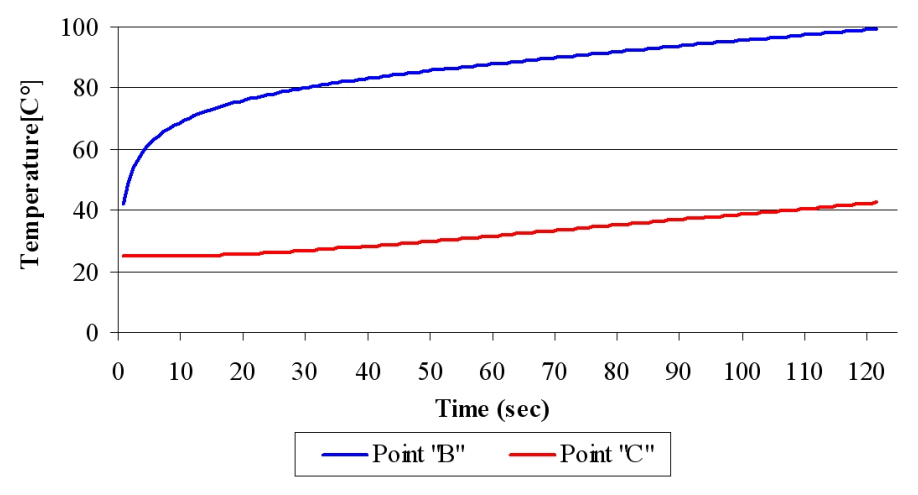

Fig. 7. Temperature development at points " $\mathrm{B}$ " and " $\mathrm{C}$ " on the brake block

Fig. 8 shows the directions of the different displacements which were calculated on the sliding surface of the brake block. The block was fixed along the bottom marked line during the expansion calculation.

Tab. 1 summarizes the displacement values of the marked "B", "C" and "D" points in Fig. 1 at discrete time moments shown in Fig. 6 .

Fig. 9 and Fig. 10 present deformations of the sliding surface on the brake block in the course of contact calculations and those arising from thermal expansion. Fig. 9 represents the displacements, in the $x$ direction, of the nodes located along the arched surface of the brake block. (The coordinate system is shown in Fig. 8).

Fig. 10 represents the radial displacements of the nodes located along the sliding surface of the brake block. The displacements were transformed to a polar coordinate system.

In the first iteration step, the brake block was at room temperature; the elastic mechanical deformation was about $0.5 \mu \mathrm{m}$ and the brake block is slightly opened. This value was neglected in case of the further calculations. By taking into consideration the block deformation component in the $x$ direction, thermal expansion curves indicate mainly radius reduction (Fig. 9) compared to the original geometry. Based on Fig. 10 it can be concluded, 
Tab. 1. Displacement values of the marked points "B", "C" and "D"

\begin{tabular}{|c|c|c|c|c|}
\hline Time [sec] & Points & $\begin{array}{l}\text { Displacement in the } \\
x \text { direction }[\mathrm{mm}]\end{array}$ & $\begin{array}{l}\text { Displacement in the } \\
z \text { direction }[\mathrm{mm}]\end{array}$ & Radial displacement [mm \\
\hline & B & $1.56 \mathrm{e}-3$ & $-4.2 e-3$ & 0.000156 \\
\hline \multirow[t]{3}{*}{12.8} & C & $-1.49 e-3$ & 0 & 0.001492 \\
\hline & D & $1.56 \mathrm{e}-3$ & $4.2 e-3$ & 0.000156 \\
\hline & B & $2.47 \mathrm{e}-3$ & $-6.61 e-3$ & 0.000227 \\
\hline \multirow[t]{3}{*}{32} & C & $-1.53 e-3$ & 0 & 0.001529 \\
\hline & $\mathrm{D}$ & $2.47 e-3$ & $6.61 \mathrm{e}-3$ & 0.000227 \\
\hline & B & $3.47 e-3$ & $-9.2 e-3$ & 0.000290 \\
\hline \multirow[t]{3}{*}{57.6} & C & $-1.20 \mathrm{e}-3$ & 0 & 0.001196 \\
\hline & D & $3.47 e-3$ & $9.2 e-3$ & 0.000290 \\
\hline & B & $5.72 e-3$ & $-1.5 e-2$ & 0.000426 \\
\hline \multirow[t]{2}{*}{121.6} & C & $1.14 \mathrm{e}-4$ & 0 & -0.000114 \\
\hline & D & $5.72 e-3$ & $1.5 e-2$ & 0.000426 \\
\hline
\end{tabular}

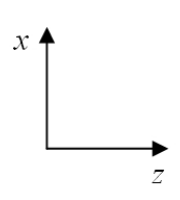

$0 \mathrm{~mm}$

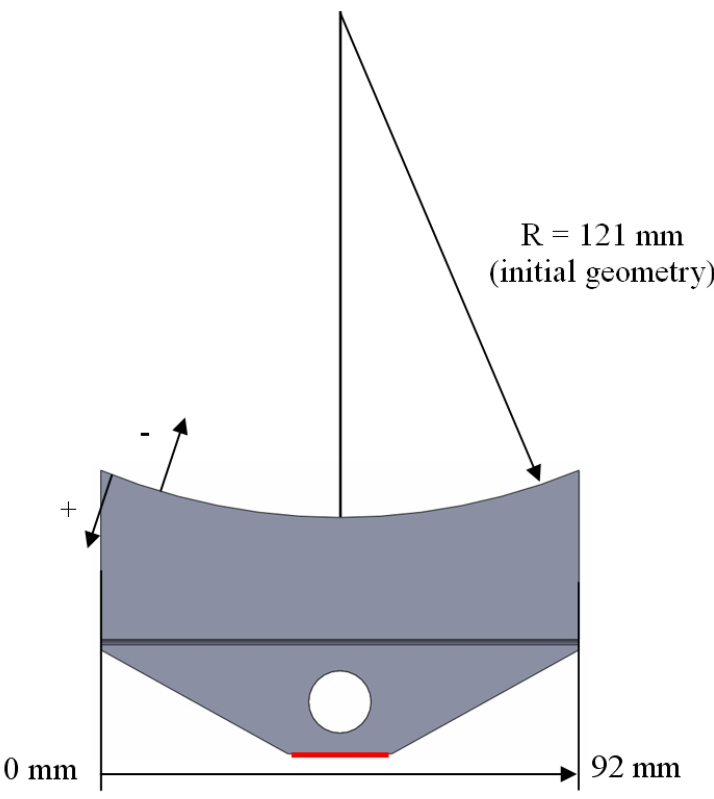

Fig. 8. Directions of the different displacements on the sliding surface of the brake block

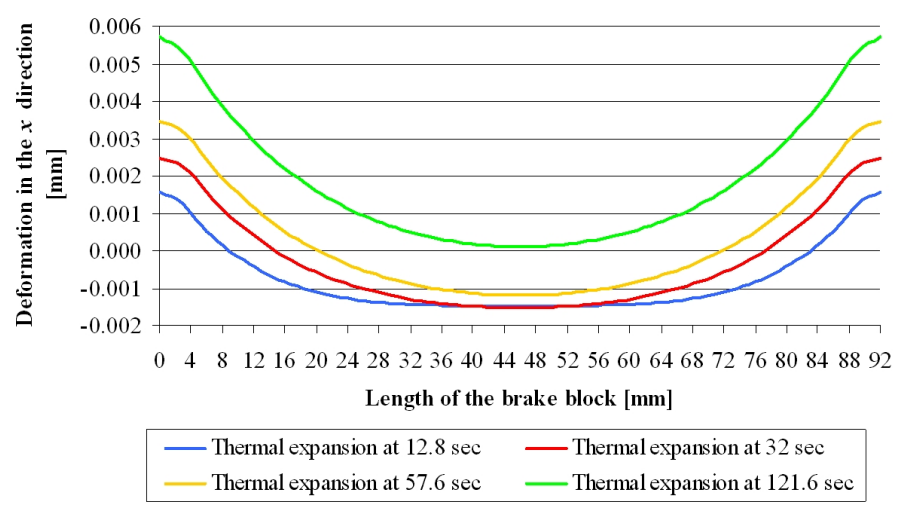

Fig. 9. Brake block deformation in the $x$ direction

that the brake block opening starts about at $t=120 \mathrm{sec}$ because the radial displacement values have negative sign at each node. The brake block has a closing process in the previous

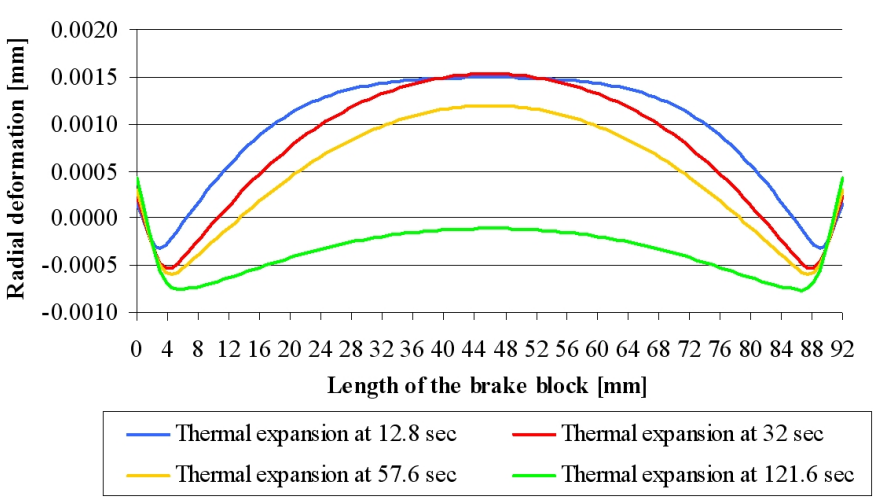

Fig. 10. Brake block deformation in the radial direction

cycles. This phenomenon is due to the fact that heat generation was only defined along the edges of the block in the time range examined, therefore larger thermal expansion occurred in this area. In order to extend the contact area towards the inside of the brake block, the phenomenon of wear should be taken into consideration. Thereby the heat load of the thermal model would progress towards the central part of the brake block, resulting in the displacement of central nodes in the $x$ direction, and the block would predominantly open.

Fig. 11 shows changes in the radius of the contact surface of the brake block with the help a circle fitted to the points "B", " $\mathrm{C}$ " and " $\mathrm{D}$ " in each investigated time step. The vectorial aggregation of deformation components in the $x$ and $z$ directions were considered at the mentioned points. The radius values are collected in Table.2 2

It can be concluded, that the change of the brake block radius is not obvious following the evaluating of the directional displacement for the marked geometrical points. Based on Fig. 11 it can be established that the expansion of the brake block is not significant, besides that the brake block opening starts about at $120 \mathrm{sec}$ regarding to the original geometry. The radius of the brake block increases with the growth of the contact surface 
Tab. 2. Radius of the circle was determined based on the displacement values of the marked points "B", "C" and "D"

\begin{tabular}{lr}
\hline Time [sec] & Radius [mm] \\
\hline 12.8 & 120.9837 \\
\hline 32 & 120.9842 \\
\hline 57.6 & 120.9891 \\
\hline 121.6 & 121.0069 \\
\hline
\end{tabular}

area. Considering a long time braking process the radius of the brake block can be about $R=121.56 \mathrm{~mm}$ when the whole contact surface of the brake block takes part in the process.

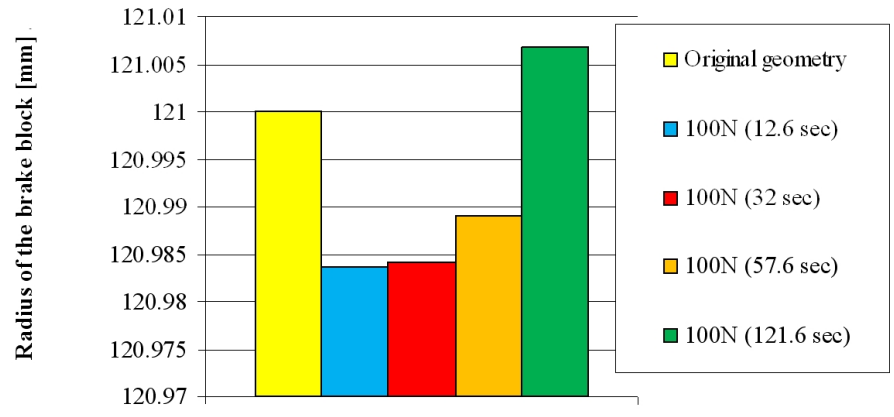

Fig. 11. Changes in the contact radius of the brake block in each load case

\subsection{Worn brake block study (Operating force $\mathrm{F}=500 \mathrm{~N}$ )}

Fig. 11] shows the thermal load of a worn brake block loaded by $F_{N}=500 \mathrm{~N}$ normal force. Thermal load locations were specified on the basis of testing experience (Fig. 13] [4]. In the test equipment, the brake block is connected to the rotating wheel by a self-adjusting solution (pinned fixing), thereby the extensions of contact surfaces are different along the top and the bottom surfaces of the brake block. (Considering the operation conditions $(v, \mu)$ of the test equipment and the heat partition of the brake block mentioned in Part 1. of this paper the thermal load of the worn brake block is $Q=245 \mathrm{~W}$ with $F_{N}=500 N$ ).

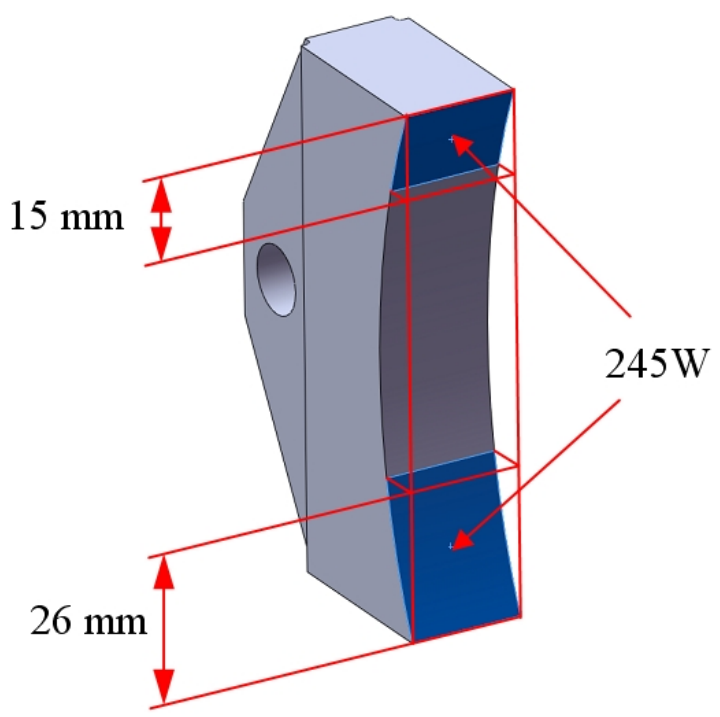

Fig. 12. Thermal load of a brake block worn off under $500 \mathrm{~N}$ normal force

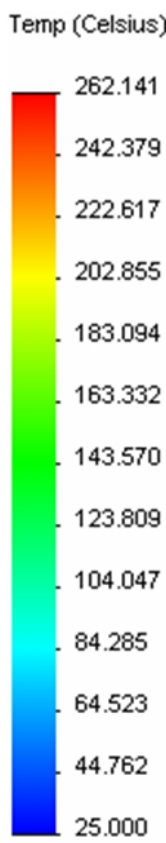

Fig. 14. Temperature distribution of a brake block worn off under $500 \mathrm{~N}$ normal force $(100 \mathrm{sec})$

Fig. 15 presents the thermal expansion in the $x$ direction of the brake block (Fig. 14) at $t=100 \mathrm{sec}$.

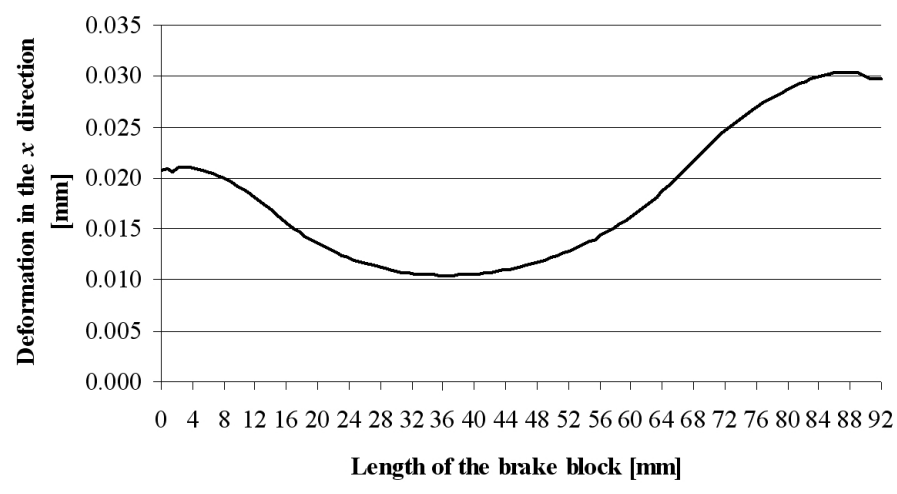

Fig. 15. Brake block deformation in the $x$ direction at the 100th second

Fig. 16 shows the brake block opening process by evaluating the radial displacements of the nodes located at the worn friction surfaces.

In the course of the experiment shown in Fig. 13, the wear of the brake block in the $x$ direction was recorded under a loading 


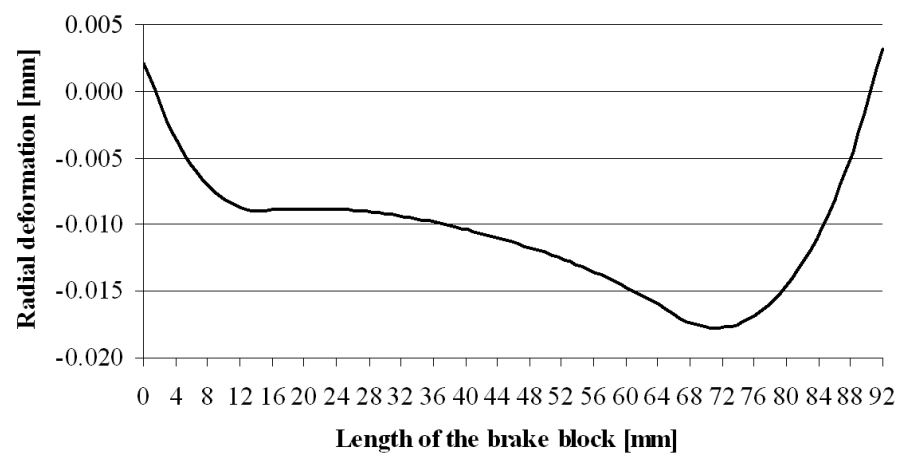

Fig. 16. Brake block deformation in the radial direction at the 100th second

\section{References}

1 Vernersson T, Thermally induced roughness of tread-braked railway wheels (Part 1): brake rig experiments, Wear, 221(2), (2007), 69-105, DOI 10.1243/0954409JRRT57

2 Liktor B, Váradi K, Kisminta féktuskó hôtani analizise, GÉP, (accepted).

3 Vernersson $\mathbf{T}$, Thermally induced roughness of tread-braked railway wheels (Part 1): modelling and field measurements, Wear, 236, (1999), 106-116, DOI 10.1016/S0043-1648(99)00261-6

4 Szúcs J, Váradi K, Zobory I, Szabó A, Féktuskó-kerékabroncs kapcsolat kopási viselkedése, GÉP, LXI, (2010/11), 28-32.

force of $500 \mathrm{~N}$, which can be considered as an extreme load case corresponding to emergency braking. In the course of measurements as a maximum, more of than $0.2 \mathrm{~mm}$ wear was registered at $t=100 \mathrm{sec}$, where the rate of thermal expansion was smaller by one order of magnitude in case of the same brake block load in the $x$ direction (Fig. 13] [4]. The maximum $x$ directional deformation the worn brake block is about fifth of the measured wear value. The thermal expansion was asymmetric considering the worn brake block behaviour (Fig. 15 and Fig. 16). The thermal expansion in the radial direction is significant in the inner part of the contact surface on the brake block, apart from edges of the contact area. In the vicinity of the two edges the radial thermal expansion is near zero because of the dominant thermal expansion in the $z$ direction (see Tab. 1) compared to the ones in the $x$ direction.

\section{Conclusion}

It can be concluded based on the thermal FE results, that there isn't any block opening process in the first $50 \mathrm{sec}$ when the thermal load has a local effect only. Block opening can be only estimated when the full friction surface of the brake block is heated. In case of a test equipment to model brake block thermal expansion, the deformation values were smaller by one order of magnitude than the rate of the wear measured. The contact area produced - including the exact place of heat generation cannot be taken into consideration by only thermal simulations. The phenomenon of brake block opening was demonstrated by a thermal load model defined along the entire contact radius, projecting the wear of the initial shape of the brake block to the diameter of the wheel. In the course of the integrated process of braking, contact surfaces in friction are primarily determined by wear processes; thermal expansion characteristics are less dominant. The results yielded support the fact that wear and thermal processes are required to be dealt with together in further phases of the research. 